\title{
Probable adverse reaction to a pharmaceutical excipient
}

\author{
C M Hall, D W A Milligan, J Berrington
}

Arch Dis Child Fetal Neonatal Ed 2004;89:F184. doi: 10.1136/adc.2002.024927

Adverse reactions to medication are well recognised although information on the incidence in children is lacking. Adverse reactions have also been attributed to a range of pharmaceutical excipients. This is a report of an adverse reaction to the excipient in clindamycin injection.

\section{CASE REPORT}

A baby boy was born to a primigravid mother at 24 weeks gestation weighing $710 \mathrm{~g}$. He received poractant (Curosurf) and mechanical ventilation for presumed surfactant deficiency lung disease. On the third day of life, he developed widespread erythema and sloughing of the skin associated with staphylococcal septicaemia which was treated with flucloxacillin and vancomycin. After he developed a red swollen right knee on day 17 and a swollen cheek on day 18 , intravenous clindamycin was prescribed in place of vancomycin. The first two doses of clindamycin were given without a problem, but after the third and fourth doses, the baby suffered a profound desaturation and chest splinting requiring resuscitation. The clindamycin was discontinued in view of concerns that there may have been a causative association. The baby suffered no obvious sequelae, there was no radiological evidence of osteomyelitis three weeks later, and he was transferred back to his local hospital well at 11 weeks of age.

It is stated in the Summary of Product Characteristics ${ }^{1}$ that the benzyl alcohol component of clindamycin injection may cause "gasping syndrome" in premature neonates, but we have been unable to find any reports in the literature specific to clindamycin. The manufacturer's pharmacovigilance department had not received any reports of this syndrome.

Benzyl alcohol is used as a preservative in many pharmaceutical formulations. In the early 1980s reports started to appear about toxicity of benzyl alcohol in neonates. Gershanik $\mathrm{et}_{\mathrm{al}} \mathrm{l}^{2}$ reported a gasping syndrome in 10 premature infants. In the United States at this time, bacteriostatic water and $\mathrm{NaCl}$ injections contained $0.9 \%$ benzyl alcohol. The infants received multiple injections from flushes and medicines reconstituted with the water and $\mathrm{NaCl}$. Benzyl alcohol is oxidised to benzoic acid, then conjugated with glycine in the liver, and excreted as hippuric acid in the urine. These infants accumulated benzyl alcohol because the pathways involved in the metabolism of benzyl alcohol in premature babies are immature. The immature pathways in combination with the relatively high dose of benzyl alcohol are thought to be the cause of the gasping syndrome. The authors reported the gasping syndrome as the most striking feature, but there were other symptoms including metabolic acidosis, intraventricular haemorrhage, and neurological problems. Sixteen neonatal deaths were reported that were thought to be due to benzyl alcohol toxicity.

After this report, the Food and Drug Administration (FDA) recommended that fluids preserved with benzyl alcohol were not to be used in premature babies. In 1986, Hiller et $a l^{3}$ retrospectively reviewed their patients before and after the solutions containing benzyl alcohol were stopped. They concluded that the toxicity of benzyl alcohol contributed to the mortality and the incidence of major intraventricular haemorrhage in babies weighing less than $1000 \mathrm{~g}$ at birth.

The FDA has approved 773 chemical agents for use as excipients in pharmaceutical formulations. ${ }^{4}$ Similar compounds are used in the United Kingdom. They are inert products added for stability reasons, as a preservative, flavouring agent, or dye. Adverse reactions to these excipients have been reported in children and include lactose intolerance, propylene glycol induced lactic acidosis, aspartame induced headache and seizures, cross sensitivity reactions to saccharin in children with sulphonamide allergy, and dye induced reactions in patients with aspirin sensitivity. ${ }^{45}$ For patients with known sensitivities to excipients, it is often difficult to quickly access the required information-not all of the excipients are listed on the label. Formulations may change and this may not always be publicised.

Moore et $a l^{6}$ found that, in their review of reports to the FDA, adverse reactions to drug therapy are a significant cause of death in infants and children. This case report illustrates the potential for serious adverse reactions to excipients to occur that may be difficult to distinguish from other medical problems. Clindamycin is rarely used in preterm neonates and is not licensed in infants of less than 1 month of age. This reaction, which could have been fatal, provides further evidence for having medicines available that have been fully tested and are licensed in children and the importance of reporting adverse reactions in children particularly when the medicines are being used in an unlicensed or off label manner.

Prescribers should be aware of the potential for excipients to cause adverse reactions in addition to the drug itself. These reactions should be reported to the UK's Committee on Safety of Medicines (CSM) using the Yellow Card Reporting Scheme in the usual way.

\section{Authors' affiliations \\ C M Hall, Pharmacy Department, Royal Victoria Infirmary, Newcastle upon Tyne, UK}

D W A Milligan, J Berrington, Neonatal Unit, Royal Victoria Infirmary

Correspondence to: Miss Hall, Pharmacy Department, Royal Victoria Infirmary, Queen Victoria Road, Newcastle upon Tyne NE1 4LP, UK

Accepted 31 January 2003

\section{REFERENCES}

1 Pharmacia. Summary of product characteristics: Dalacin C phosphate injection. Pharmacia Ltd, UK.

2 Gershanik J, Boecler B, Ensley $\mathrm{H}$, et al. The gasping syndrome and benzyl alcohol poisoning. N Engl J Med 1982;307:1384-8

3 Hiller JL, Benda GI, Rahatzad M, et al. Benzyl alcohol toxicity: impact on mortality and intraventricular hemorrhage among very low birth weight infants. Pediatrics 1986;77:500-6.

4 American Academy of Pediatrics Committee on Drugs. "Inactive" ingredients in pharmaceutical products: update (subject review). http://www.aap.org/ policy/re9706.html.

5 Pawar S, Kumar A. Issues in the formulation of drugs for oral use in children. Pediatr Drugs 2002;4:371-9.

6 Moore TJ, Weiss SR, Kaplan S, et al. Reported adverse drug events in infants and children under 2 years of age. http://www.pediatrics.org/cgi/content/ full/110/5/e53. 